\title{
The impact of pelvic floor multidisciplinary team on patient management: the experience of a tertiary unit
}

This article was published in the following Dove Medical Press journal: Journal of Multidisciplinary Healthcare

\author{
Ivilina Pandeva' \\ Suzanne Biers ${ }^{2}$ \\ Ashish Pradhan' \\ Vandna Verma' \\ Mark Slack' \\ Nikesh Thiruchelvam² \\ 'Department of Urogynecology, \\ Addenbrooke's Hospital, \\ Cambridge, UK; ${ }^{2}$ Department of \\ Urology, Addenbrooke's Hospital, \\ Cambridge, UK
}

Correspondence: Ivilina Pandeva Department of Urogynecology, Addenbrooke's Hospital, Hills Road, CB2 OQQ, Cambridge, UK

Tel +44 I223586740

Fax +44 I223586 59I

Email ivilina.pandeva@gmail.com
Purpose: Pelvic floor dysfunction is a common and heterogenous condition with numerous clinical manifestations, making the optimal management challenging. The traditional single-specialty approach may fail to address its complex nature. Currently, there are no published data on the impact of joint pelvic floor multidisciplinary team (MDT) meetings on patient management.

Patients and methods: This study represents a retrospective analysis of prospectively collected data on female patients discussed at a joint pelvic floor MDT over a 12-month period in a tertiary referral center.

Results: One hundred fifty-two cases were included with a median age of 55 years (range 18-83) and a BMI of $32 \mathrm{~kg} / \mathrm{m}^{2}$ (range 17-58). Lower urinary tract dysfunction was the predominant symptom in $75 \%(114 / 152)$. The pelvic organ prolapse symptom of a vaginal bulge was present in $11 \%(17 / 152)$. All cases of vaginal prolapse were accompanied by either urinary incontinence, $59 \%(10 / 17)$, or obstructive defecation, $41 \%$ (7/17). Fecal incontinence was recorded in $10 \%$ $(15 / 152)$. Mesh-related complications were reported in 3\% (4/152). The MDT recommended a change in the initial management plan in $20 \%$ (31/152) of cases, of whom $80 \%(25 / 31)$ were patients with complex urinary incontinence. The MDT agreed a change in the primary care team in $16 \%(25 / 152)$ of cases.

Conclusion: There is an increasing regulatory requirement for patients with pelvic floor dysfunction to be discussed in an MDT setting. Findings demonstrate that joint pelvic floor MDT meetings are feasible and contribute to a change in the management of complex patients. Keywords: MDT, multidisciplinary team, pelvic floor dysfunction, prolapse, incontinence

\section{Introduction}

Pelvic floor dysfunction (PFD) typically presents with disruption of normal function and includes a wide spectrum of different conditions such as urge and stress urinary incontinence (SUI), fecal incontinence, pelvic organ prolapse, abnormality in lower urinary tract, and defecatory dysfunction. ${ }^{1,2}$ PFD can affect women at any stage of their life, but remains more common with age progression affecting $40 \%$ of women at $65-70$ years and $50 \%$ of those $>80$ years. ${ }^{3}$ PFD is a heterogenous condition with a complex pathophysiology and numerous clinical manifestations, making the optimal management of PFD a significant challenge. ${ }^{4}$ It has also been estimated that $\sim 24 \%$ of adult women have symptoms of at least one PFD. ${ }^{3}$ Currently, nearly $20 \%$ of women undergo surgery for either urinary incontinence or prolapse in their lifetime, with about $30 \%$ requiring further surgery for symptom recurrence. ${ }^{5,6}$ It is thought that the service demand for the management of PFD will rise by $50 \%$ due to an aging population and 
rising levels of obesity. ${ }^{7,8}$ Further factors such as obesity and some comorbidities are also having an impact on the incidence of PFD. ${ }^{3,9}$ Overweight and obese women are nearly twice more likely to report symptoms of PFD than women with normal body mass index. ${ }^{3,10}$

The management of these patients can be challenging and often requires input from various health professionals. The traditional compartmentalized single-specialty approach to PFD meant that patients with symptoms and pathology affecting the female reproductive organs, the lower urinary and/or the gastrointestinal tracts were seen only by a single specialist, whose expertise did not necessarily span all three domains. This has been associated with inferior outcomes, including incomplete resolution of symptoms and high failure rates after surgery. ${ }^{6,11}$ As a result, the National Institute for Health and Clinical Excellence (NICE) recommended multidisciplinary team (MDT) management of patients with PFD to standardize treatment and improve patient outcomes. ${ }^{12}$

Currently, there is no clear evidence in the literature of the impact of joint pelvic floor MDT meetings on patient's management. The aim of this study was to evaluate their role in the management of women with PFD in the setting of an MDT.

\section{Materials and methods}

This is a retrospective analysis of prospectively collected data of all women referred to and discussed at Joint Pelvic Floor MDT between January 2015 and January 2016 in a tertiary referral center. This project was registered with the Cambridge University Hospital Clinical Effectiveness Unit. Data were collected by using the hospital electronic records system EPIC (Epic Systems Corporation, Madison, WI, USA).

Patient-specific details including age, BMI, and presenting symptoms were recorded. Information collected also included attendance of the individual team members from different disciplines, the time from initial clinic review to decision for MDT referral and further time to MDT discussion. The initially formulated management plan was compared to the final MDT recommendation to identify if there was a change in the management plan including type of surgery, surgeon, or management team.

The Joint Pelvic Floor MDT consisted of subspecialist urogynecologists, urologists (subspecialists in functional and female urology), colorectal surgeons with an interest in functional bowel disorders, and nurse specialists. This is in keeping NICE recommendations. ${ }^{12}$ Advice was also available from care of the elderly physicians, radiologists, and physiotherapists. The meetings were scheduled twice a month for 60-180 minutes. The attendance of at least one consultant urogynecologist and one consultant urologist was required for the meeting to be considered quorate. The consultant colorectal surgeon did not attend if there were no cases affecting the gastrointestinal tract, although the colorectal nurse specialist represented the team at the meeting in their absence.

An electronically submitted proforma was developed to capture the essential patient information (Figure 1). Cases were presented by the team who generated the referral from their department and the electronic patient record on EPIC was reviewed in detail including clinical correspondence, quality-of-life questionnaires, and results of investigations (eg, bladder diaries, urodynamic traces, and imaging). Minutes were kept and MDT recommendations were documented by one of two consultant urologists using the proforma, which was visible to all MDT members on a projected screen. This was automatically saved onto the electronic patient record. A letter was also sent to the general practitioner ${ }^{13}$ and to the patient detailing the outcome of joint MDT meeting and plan for further management.

\section{Results}

One hundred fifty-two women were referred to the Joint Pelvic Floor MDT between January 2015 and January 2016 (see Table 1). All 152 cases were discussed (100\%) and details are summarized in Bamboat et al. ${ }^{14}$ The median age of patients discussed was 55 years (range 18-83) with a median BMI of $32 \mathrm{~kg} / \mathrm{m}^{2}$ (range 17-58). During the 12-month study period, there were 24 meetings. The median number of patients discussed was 5 (range 3-20). All sessions were attended by at least one consultant urologist and one consultant urogynecologist. Table 2 presents information on meetings' attendance, referring specialty, and timelines from initial presentation to decision for referral and from referral to discussion. Both consultant urologists attended $54 \%$ of meetings and both consultant urogynecologists were present in 58\%. Consultant colorectal surgeons were present in $42 \%$ of cases, with their specialist nurse attending $58 \%$ of meetings. Sixty percent of cases for MDT review were referred by urogynecology, $32 \%$ by urology, and $8 \%$ by colorectal surgery. Median time from first clinic visit to decision for MDT referral was 42 days, ranging from 1 to 385 days. The median time from referral to MDT discussion and outcome was 20 days (range $1-75$ ).

Table 3 details the initial presenting complaint and MDT outcomes. In $75 \%(114 / 152)$ of cases, the predominant 


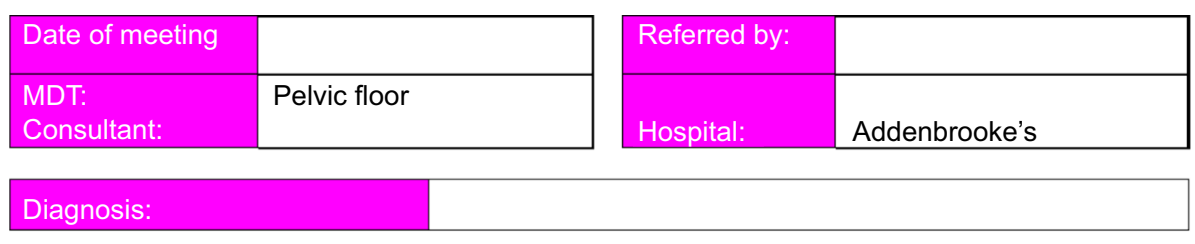

\section{Referring clinician's summary:}

Case discussion/review of radiology (delete as needed)

Reason for referral to MDT:

First presentation/recurrence (delete as needed)

\section{MDT action plan:}

\section{Key worker:}

Figure I Joint pelvic floor MDT proforma.

Abbreviation: MDT, multidisciplinary team.

Table I Background characteristics

\begin{tabular}{|l|l|l|}
\hline Demographic & Median & Range \\
\hline Age (years) & 55 & $18-83$ \\
Body mass index $\left(\mathrm{kg} / \mathrm{m}^{2}\right)$ & 32 & $17-58$ \\
Investigations prior to MDT & Number & $\%^{\mathrm{a}}$ \\
UDS & $56 / 152$ & 37 \\
VUDS & $42 / 152$ & 28 \\
Ambulatory UDS & $5 / 152$ & 3 \\
EUA tendoscopy & $21 / 152$ & 14 \\
Imaging (US; CT; MRI; renogram) & $20 / 152$ & 13 \\
PNE & $9 / 152$ & 6 \\
\hline
\end{tabular}

Note: aPercent adds to more than 100 as some patients had two or more investigations.

Abbreviations: $\mathrm{CT}$, computer tomography; EUA, examination under anesthesia; MDT, multidisciplinary team; MRI, magnetic resonance imaging; PNE, percutaneous nerve evaluation; UDS, urodynamics; US, ultrasound; VUDS, video urodynamics.

presenting symptoms were those of lower urinary tract dysfunction $-35 \%$ (40/114) with SUI, 32\% (36/114) with mixed urinary incontinence (MUI), and 22\% (25/114) with urge urinary incontinence (UUI). The pelvic organ prolapse symptom of a vaginal bulge was present in $11 \%(17 / 152)$. All cases of vaginal prolapse were accompanied by bothersome symptoms of either urinary incontinence, $59 \%(10 / 17)$,
Table 2 Details of MDT meetings including attendance, referring specialty, and timelines

\begin{tabular}{|l|l|l|}
\hline Meetings attendees & Number & $\%$ \\
\hline Two urologists & $13 / 24$ & 54 \\
Two urogynecologists & $14 / 24$ & 58 \\
Colorectal surgeon & $10 / 24$ & 42 \\
Colorectal specialist nurse & $14 / 24$ & 58 \\
Urogynecology specialist nurse & $9 / 24$ & 38 \\
Urology specialist nurse & $2 / 24$ & 8 \\
\hline Referring specialty & Number & $\%$ \\
\hline Urogynecology & $91 / 152$ & 60 \\
Urology & $49 / 152$ & 32 \\
Colorectal surgery & $12 / 152$ & 8 \\
\hline Timelines (days) & Median & Range \\
\hline Presentation to MDT referral & 42 & $1-385$ \\
Referral to MDT outcome & 20 & $1-75$ \\
\hline
\end{tabular}

Abbreviation: MDT, multidisciplinary team.

or obstructive defecation, $41 \%$ (7/17). Fecal incontinence was present in $9 \%$ (14/152). Other symptoms of vaginal stenosis, vaginal pain, and urethral discharge were reported in $2 \%(3 / 152)$. Mesh-related complications were present in $3 \%(4 / 152)$. 
Table 3 Predominant symptoms, change in management and management team

\begin{tabular}{|c|c|c|c|}
\hline $\begin{array}{l}\text { Predominant } \\
\text { symptom }\end{array}$ & \begin{tabular}{|l|} 
No. of \\
cases I52 \\
$(\%)$ \\
\end{tabular} & $\begin{array}{l}\text { Change in } \\
M X 31 / 152 \\
(20 \%)\end{array}$ & $\begin{array}{l}\text { Change in } \\
\text { MX team } \\
25 / 152(16 \%)\end{array}$ \\
\hline LUTS & $114(75 \%)$ & $25(16 \%)$ & $16(11 \%)$ \\
\hline MUI & $36(33 \%)$ & 10 & 8 \\
\hline SUI & $40(35 \%)$ & 6 & 7 \\
\hline UUI & $25(22 \%)$ & 8 & 0 \\
\hline Voiding dysfunction & $4(3 \%)$ & 0 & 0 \\
\hline Recurrent UTI & $4(3 \%)$ & 1 & $\mathrm{I}$ \\
\hline BPS & $4(3 \%)$ & 0 & 0 \\
\hline POP & $17(11 \%)$ & 2 (I.3\%) & $9(6 \%)$ \\
\hline $\mathrm{POP}+\mathrm{UI}$ & $10(59 \%)$ & 2 & 2 \\
\hline $\begin{array}{l}\text { POP + obstructive } \\
\text { defecation }\end{array}$ & 7 (4I\%) & 0 & 7 \\
\hline Other & $7(5 \%)$ & $3(2 \%)$ & 0 \\
\hline $\begin{array}{l}\text { Vaginal stenosis } \\
\text { Urethral discharge } \\
\text { Pain }\end{array}$ & $3(2 \%)$ & 2 & \\
\hline Mesh related & $4(3 \%)$ & I & \\
\hline FI & $14(9 \%)$ & I (0.7\%) & 0 \\
\hline
\end{tabular}

Abbreviations: BPS, bladder pain syndrome; $\mathrm{FI}$, fecal incontinence; LUTS, lower urinary tract dysfunction; MX, management; MUI, mixed urinary incontinence; POP, pelvic organ prolapse; SUI, stress urinary incontinence; UI, urinary incontinence; UTI, urinary tract infection; UUI, urge urinary incontinence.

The MDT recommended a change in the initial management plan in 20\% (31/152) of cases. Eight percent (25/31) of these changes were in patients with complex urinary incontinence cases (eg, failed primary treatment, those requiring secondary surgery or coexisting symptoms involving multiple pelvic compartments): ten of these had predominant symptoms of MUI; six presented with SUI and eight cases with UUI. There were two cases of coexisting pelvic organ prolapse and urinary incontinence where the MDT recommendation deviated from the primary management plan. Other cases (3/31) where management was altered included vaginal stenosis, urethral discharge, and pain following previous retropubic tape procedure. The MDT agreed a change in management team in $16 \%(25 / 152)$ of cases. These included colorectal management in six of the primary urogynecological and one of urological cases. Sixteen cases were referred from urogynecology to urology for the management of recurrent UI and recurrent urinary tract infections. Urology referred to urogynecology two cases for the management of concurrent pelvic organ prolapse and urinary incontinence. In $3 \%(4 / 152)$ of cases, changes were recommended in both management plan and management team. Three of those cases were for the management of MUI and one for the management of coexisting obstructive defecation syndrome and urinary incontinence.

\section{Discussion}

This is the first study to review the impact of Joint Pelvic Floor MDT discussions on decision-making and patient management. The rationale for involving specialists from different fields in the management of PFD is the close anatomical and functional relationship of the lower urinary tract, lower genital tract, and anorectum, resulting in symptoms affecting multiple compartments. ${ }^{15,16}$

The concept of MDT was initially introduced to standardize cancer care in the United Kingdom, following the publication of the Calman-Hine report in 1995 which demonstrated that the multidisciplinary approach improves outcomes. ${ }^{17}$ This philosophy has been adopted by both regulatory and professional societies across the breadth of health care with the aim of improving patient outcomes and promoting crossspeciality collaboration and team working. ${ }^{18-21}$

In the setting of PFD, NICE recommended MDT discussion prior to any invasive therapy for the management of overactive bladder or stress incontinence. ${ }^{12}$ They suggested a PFD MDT should include a urogynecologist, a urologist with special interest in female urology, a specialist nurse, a women's health physiotherapist, a colorectal surgeon, and a specialist nurse with interest in bowel dysfunction management and a care of the elderly physician. ${ }^{12}$ While not all centers in the United Kingdom have the infrastructure or personnel for an extended pelvic floor MDT, a survey of members of the Pelvic Floor Society found that $84 \%$ of tertiary and $75 \%$ of regional units held some form of regular MDT meetings. ${ }^{22}$

Our center largely follows this NICE recommendation with core team members from urology, urogynecology, and colorectal surgery as well as specialist nursing and physiotherapy input. Given the median age of patients in our service is 55 years, it was felt that routine attendance of a care of the elderly physician would not be cost-effective or an efficient use of their time, however, we do have a dedicated referral pathway for their input or attendance should be required. As reported in the literature, increasingly, patients require complex imaging; so, in the future involvement of a radiologist with special interest in pelvic floor imaging may also need to be considered as a core member of the joint pelvic floor service. ${ }^{23}$

Age of the patients in our study ranged from 18 to 83 (median of 55) years and is consistent with previous reports that PFD affects women across all ages, albeit more common in the menopause. ${ }^{1,3,24}$

In our study, MDT discussion led to a change in management plan in $20 \%$ of patients referred to joint pelvic 
floor MDT. This is in line with work in other complex urogynecological conditions: Rao et al reported alteration in the management plan in $25 \%$ of complex uro-oncology cases following MDT discussion. They also reported 33.3\% of patients moved to primary treatment specialty following discussion, ${ }^{25}$ compared with $16 \%$ in our study. This cross-specialty referral resulting from MDT discussion is important for ensuring patients are seen expeditiously by the most appropriate team. Although we have identified a change in management and assume its beneficial role, we appreciate that we cannot correlate this to clinical patients' outcomes.

However, a multidisciplinary approach in the management of such patients translates into a more holistic evaluation and management and facilitates joint operating and better collaboration between specialties. There is also evidence to suggest that MDT management of patients encourages research in terms of setting up multidisciplinary trials. ${ }^{26}$

In line with the recommendations from the recent Independent Medicines and Medical Devices Safety Review on the use of surgical mesh for SUI, PFMDT provides a forum for discussion of management of complex cases but also encourages regular audit of operations, outcomes, and complications. ${ }^{27,28}$ Although in this series there were only four cases $(3 \%)$ of mesh-related complications, we expect that these numbers will increase within tertiary setting with centralization of mesh referrals and the establishment of mesh centers. ${ }^{29}$

Despite these advantages, MDT meetings do carry a significant cost, are time-consuming taking specialists away from direct patient care and may lead to delays in patient care. ${ }^{23}$ Refinement of criteria for referral to joint MDT may address some of these. Based on our work, while $20 \%$ had a change in their management, $80 \%$ did not. With increasing experience, this may mean that we can develop more stringent criteria for referral to the MDT such as complex incontinence cases with failed primary treatment, those requiring secondary surgery or coexisting symptoms affecting multiple pelvic compartments. These subsequently can be audited regularly using tools that assess MDT's quality and efficacy. ${ }^{30}$ Further, the engagement of other regional referral centers can be expanded and encouraged by using tele-medicine. Given the recommendations of various national and international bodies, there is a clear role for an MDT in the management of complex pelvic floor disorders cases. It ensures optimal care to patients where the full range of therapeutic options are considered, improves collaboration between specialties, and provides an excellent learning and teaching opportunity.

\section{Conclusion}

Following recommendations by numerous international bodies, there is a growing regulatory requirement for patients with complex pelvic floor disorders to be discussed in an MDT setting. Here, we demonstrate that these meetings are feasible and lead to a change in the management of complex patients. As these meetings evolve, there is a scope to further define what is meant by "complex" disease and refine the inclusion criteria to ensure they remain cost-effective and relevant.

\section{Acknowledgment}

The abstract of this paper was presented at the ICS Conference Florence 2017 as a poster presentation with interim findings. The poster's abstract was published in "Poster Abstracts" in Journal of Clinical Urology, 2017;10(5):414; http://journals. sagepub.com/doi/full/10.1177/2051415817698596.

\section{Disclosure}

The authors report no conflicts of interest in this work.

\section{References}

1. Weber AM, Abrams P, Brubaker L, et al. The standardization of terminology for researchers in female pelvic floor disorders. Int Urogynecol J Pelvic Floor Dysfunct. 2001;12(3):178-186.

2. Bo K, Frawley HC, Haylen BT, et al. An International Urogynecological Association (IUGA)/International Continence Society (ICS) joint report on the terminology for the conservative and nonpharmacological management of female pelvic floor dysfunction. Neurourol Urodyn. 2017;36(2):221-244.

3. Nygaard I, Barber MD, Burgio KL, et al; Pelvic Floor Disorders Network. Prevalence of symptomatic pelvic floor disorders in US women. JAMA. 2008;300(11):1311-1316.

4. Nager CW, Kumar D, Kahn MA, Stanton SL. Management of pelvic floor dysfunction. Lancet. 1997;350(9093):1751.

5. Wu JM, Matthews CA, Conover MM, Pate V, Jonsson Funk M. Lifetime risk of stress urinary incontinence or pelvic organ prolapse surgery. Obstet Gynecol. 2014;123(6):1201-1206.

6. Olsen AL, Smith VJ, Bergstrom JO, Colling JC, Clark AL. Epidemiology of surgically managed pelvic organ prolapse and urinary incontinence. Obstet Gynecol.1997;89(4):501-506.

7. Delancey JO. The hidden epidemic of pelvic floor dysfunction: achievable goals for improved prevention and treatment. Am J Obstet Gynecol. 2005;192(5):1488-1495.

8. Kelly T, Yang W, Chen CS, Reynolds K, He J. Global burden of obesity in 2005 and projections to 2030. Int JObes (Lond). 2008;32(9):1431-1437.

9. Button BM, Holland AE, Sherburn MS, Chase J, Wilson JW, Burge AT. Prevalence, impact and specialised treatment of urinary incontinence in women with chronic lung disease. Physiotherapy. Epub 2018 Jul 30.

10. Hendrix SL, Clark A, Nygaard I, Aragaki A, Barnabei V, McTiernan A. Pelvic organ prolapse in the women's health initiative: gravity and gravidity. Am J Obstet Gynecol. 2002;186(6):1160-1166.

11. Mowat A, Maher D, Baessler K, Christmann-Schmid C, Haya N, Maher C. Surgery for women with posterior compartment prolapse. Cochrane Database Syst Rev. 2018;3:CD012975.

12. NICE. Urinary Incontinence in Women. The Management of Urinary Incontinence in Women. London: National Institute of Clinical Excellence CG171. Royal College of Obstetricians and Gynaecologists; 2013.

13. Liu Z, Yang L, Cui Y, et al. IL-21 enhances NK cell activation and cytolytic activity and induces Th17 cell differentiation in inflammatory bowel disease. Inflamm Bowel Dis. 2009;15(8):1133-1144. 
14. Bamboat ZM, Stableford JA, Plitas G, et al. Human liver dendritic cells promote T cell hyporesponsiveness. J Immunol. 2009;182(4):1901-1911.

15. Meyer I, Richter HE. Impact of fecal incontinence and its treatment on quality of life in women. Womens Health (Lond Engl). 2015;11(2):225-238.

16. Bezerra LR, Vasconcelos Neto JA, Vasconcelos CT, et al. Prevalence of unreported bowel symptoms in women with pelvic floor dysfunction and the impact on their quality of life. Int Urogynecol J. 2014;25(7):927-933.

17. Morris E, Haward RA, Gilthorpe MS, Craigs C, Forman D. The impact of the Calman-Hine report on the processes and outcomes of care for Yorkshire's colorectal cancer patients. Br J Cancer. 2006;95(8):979-985.

18. Guidance and support for NHS surgeons on tape and mesh implants. Available from: https:/www.gov.uk/government/publications/guidanceand-support-for-nhs-surgeons-on-tape-and-mesh-implants. Accessed February 20, 2019.

19. Mcguire EJ, Lytton B. Pubovaginal sling procedure for stress incontinence. J Urol. 1978;119(1):82-84.

20. Adams E HS, Iskander M, Ballard P, Fayyad A (Clinical Governance Committee BSUG), freeman R, Toozs-Hobson P, Smith ARB. Standards for service provision in urogynaecology units. The British Society of Urogynaecology. Availabel from: www.bsug.org.uk 2012. Accessed September 07, 2018.

21. Vaizey C NK, Collins B, Dalrymple J, Church J, Lloyd D. Commissioning guide: Faecal incontinence. Available from: www.acpgbi.org. uk, 2017. Accessed September 07, 2018.
22. Hainsworth AJ, Schizas AM, Brown S, Williams AB. The future of pelvic floor services in the UK. Colorectal Dis. 2016;18(11):1087-1093.

23. De Ieso PB, Coward JI, Letsa I, et al. A study of the decision outcomes and financial costs of multidisciplinary team meetings (MDMs) in oncology. Br J Cancer. 2013;109(9):2295-2300.

24. Dieter AA, Wilkins MF, Wu JM Epidemiological trends and future care needs for pelvic floor disorders. Curr Opin Obstet Gynecol. 2015;27(5):380-384.

25. Rao K, Manya K, Azad A, et al. Uro-oncology multidisciplinary meetings at an Australian tertiary referral centre--impact on clinical decisionmaking and implications for patient inclusion. BJU Int. 2014;114(Suppl. 1):50-54.

26. Kuroki L, Stuckey A, Hirway P, et al. Addressing clinical trials: can the multidisciplinary tumor board improve participation? A study from an academic women's cancer program. Gynecol Oncol. 2010;116(3):295-300.

27. Wise J. Surgical mesh for stress urinary incontinence to be halted immediately in England. BMJ. 2018;362:k3035.

28. Department of Health and Social Care. Update on the independent medicines and medical device safety review: written statement-HCWS 841. July10, 2018.

29. NHS England. Mesh Oversight Group report. 2017.

30. Lamb BW, Sevdalis N, Vincent C, Green JS. Development and evaluation of a checklist to support decision making in cancer multidisciplinary team meetings: MDT-QuIC. Ann Surg Oncol. 2012;19(6):1759-1765.
Journal of Multidisciplinary Healthcare

\section{Publish your work in this journal}

The Journal of Multidisciplinary Healthcare is an international, peerreviewed open-access journal that aims to represent and publish research in healthcare areas delivered by practitioners of different disciplines. This includes studies and reviews conducted by multidisciplinary teams as well as research which evaluates the results or conduct of such teams or health

\section{Dovepress}

care processes in general. The journal covers a very wide range of areas and welcomes submissions from practitioners at all levels, from all over the world The manuscript management system is completely online and includes a very quick and fair peer-review system. Visit http://www.dovepress.com/ testimonials.php to read real quotes from published authors. 